\title{
REVIEW
}

\section{Cerebral microbleeds: overview and implications in cognitive impairment}

\author{
Sergi Martinez-Ramirez*, Steven M Greenberg and Anand Viswanathan
}

\begin{abstract}
Cerebral microbleeds (MBs) are small chronic brain hemorrhages which are likely caused by structural abnormalities of the small vessels of the brain. Owing to the paramagnetic properties of blood degradation products, MBs can be detected in vivo by using specific magnetic resonance imaging (MRI) sequences. Over the last decades, the implementation of these MRI sequences in both epidemiological and clinical studies has revealed MBs as a common finding in many different populations, including healthy individuals. Also, the topographic distribution of these MBs has been shown to be potentially associated with specific underlying vasculopathies. However, the clinical and prognostic significance of these small hemorrhages is still a matter of debate as well as a focus of extensive research. In this article, we aim to review the current knowledge on the pathophysiology and clinical implications of MBs, with special emphasis on the links between lobar MBs, cerebral amyloid angiopathy, and Alzheimer's disease.
\end{abstract}

\section{Introduction}

Cerebral microbleeds (MBs) are small chronic brain hemorrhages, likely caused by structural abnormalities of the small vessels. The paramagnetic properties of blood degradation products make possible the visualization of $\mathrm{MBs}$ in vivo, using specific magnetic resonance imaging sequences. Extensive research has demonstrated the value of MBs as markers of small-vessel disease. Indeed, specific topographic patterns of MBs are thought to be representative of particular underlying vasculopathies, mainly cerebral amyloid angiopathy and hypertensive vasculopathy. As such, MBs are regularly identified in individuals from stroke and memory clinics, where they might have implications in therapeutic management. Interestingly, MBs are also a common finding in other populations, even in healthy elderly individuals. The clinical and prognostic significance of MBs in all these settings remains poorly understood. In this review, we aim to summarize the current knowledge on the pathophysiology and clinical implications of MBs, with special emphasis on the links between lobar MBs, cerebral amyloid angiopathy and Alzheimer's disease.

\footnotetext{
* Correspondence: srmartinez@partners.org

Philip J. Kistler Stroke Research Center, Massachusetts General Hospital, 175 Cambridge Street Suite 300, Boston, MA 02114, USA
}

\section{Review}

\section{Description and epidemiology}

From a pathological point of view, MBs are tiny deposits of blood degradation products (mainly hemosiderin) contained within macrophages and in close spatial relationship with structurally abnormal vessels. Hemosiderin is a strong paramagnetic material, which allows its detection when a magnetic field is applied [1]. This phenomenon, called susceptibility effect, is the basis of T2*-gradient recalled echo (GRE) imaging, which led to the definition of the current concept of radiological MBs [2] (Figure 1). Over time, further sequences have been developed, including three-dimensional T2*-GRE [3] and the most sensitive one to date - susceptibilityweighted imaging (SWI) [4]. Furthermore, the upgrade of several MRI parameters, such as the magnetic field, has also contributed to a more sensitive detection of MBs [5,6]. For instance, 7-Tesla MRI detects twice as many MBs in comparison to conventional 1.5-Tesla MRI [7]. The downsides of these technical improvements are the increase in the 'blooming effect' (larger visual appearance of MBs on MRI than the actual size of the hemosiderin deposit) [8] and the frequency of $\mathrm{MB}$ mimics, which raises concerns about potential 'overdetection' of MBs and a limited clinical significance (especially if supporting pathological data are not available). Also, the variation of parameters causes difficulties for a unified definition of MBs. Still, consensus guidelines on 


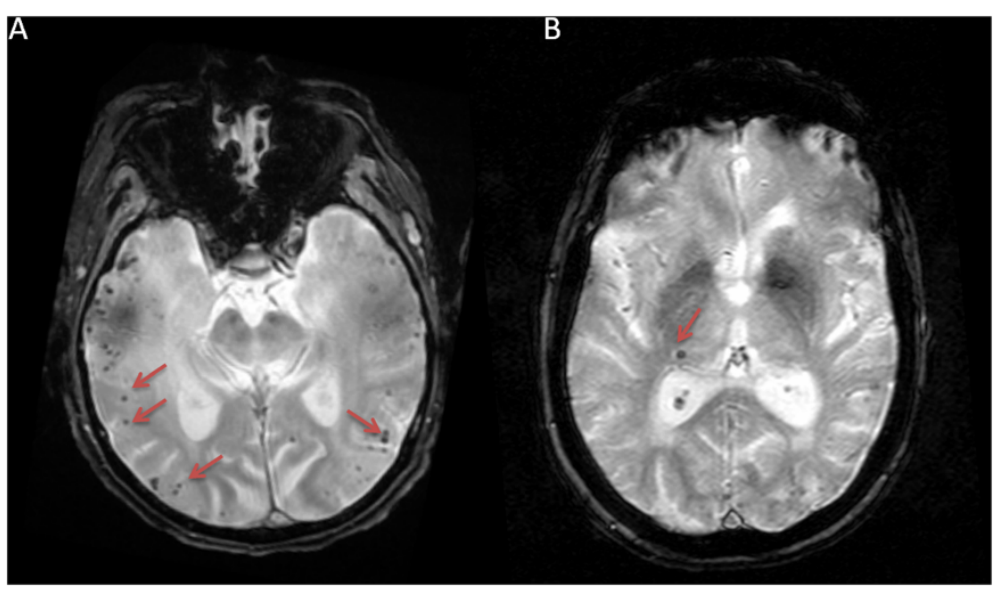

Figure 1 Cerebral microbleeds as seen on magnetic resonance imaging gradient-recalled echo imaging (arrows). (A) Multiple lobar microbleeds distributed across the temporal lobes. (B) Isolated deep microbleed in the lateral aspect of the right thalamus.

MB detection and interpretation have been published [9]. Based on these guidelines, MBs can be described as small areas of signal void with associated 'blooming', excluding non-hemorrhagic causes of signal void. Concerning $\mathrm{MB}$ size, a study on hemorrhage volumes in patients with cerebral amyloid angiopathy (CAA) found a bimodal distribution, instead of a continuum, with a large gap between the two peaks representing MBs and macrobleeds. This argued against setting a strict limit for the maximum diameter of MBs; however, the study reported a value of $5.7 \mathrm{~mm}$ as the best cutoff to distinguish between the two types of hemorrhages [10].

MBs were first reported in association with intracerebral hemorrhage ( $\mathrm{ICH})$ [11]. After this initial study, reports of MBs in $\mathrm{ICH}$ and other populations have dramatically increased. As the frequency of MBs varies enormously depending on the MRI study characteristics and the selection of the study subjects, the reported prevalence in different clinical conditions has considerably wide ranges: $47 \%$ to $80 \%$ in $\mathrm{ICH}[12,13], 18 \%$ to $71 \%[12,14]$ in ischemic stroke, or $17 \%$ to $46 \%$ in cognitive decline/dementia [15]. However, even given the lowest estimates, it appears that MBs are a common phenomenon across different patient populations. On the other hand, several populationbased studies have also reported on $\mathrm{MB}$ prevalence in healthy older individuals, which can be as high as $23.5 \%$ [16]. This observation raises questions about the pathological significance of $\mathrm{MBs}$ and the importance of $\mathrm{MB}$ detection in asymptomatic individuals.

\section{Pathological significance}

Neuroimaging studies have consistently reported associations between $\mathrm{MB}$, vascular risk factors (age and hypertension) and previously well-established markers of small-vessel disease (SVD), such as lacunar infarcts and white matter hyperintensities (WMHs) [17]. Also, a high frequency of $\mathrm{MBs}$ in severe vascular conditions like ischemic and hemorrhagic stroke has been noticed [17]. Taken together, these observations strongly support MBs as an additional marker of SVD.

A few small histopathological studies have provided insight into the vascular anomalies associated with MBs [8,18-21]. In these studies, two main forms of vasculopathies have been associated with MBs in the aging brain: CAA and hypertensive vasculopathy (HV). CAA is caused by the accumulation of $\beta$-amyloid on the vessel walls of cortical and leptomeningeal arteries. HV, a consequence of long-standing hypertension over the microvasculature of the brain, is pathologically defined by the presence of lipofibrohyalinosis, which affects mostly the deep penetrating arterioles. As both entities are associated with age, they may coexist in a single individual, with variable degrees of severity [8].

Because of the differential topographic preference of CAA and HV, MBs associated with these two entities could be expected to follow similar distributions: strictly lobar (cortical-subcortical regions of brain lobes and cerebellum) in CAA; strictly deep (deep white matter, basal ganglia, thalamus, brainstem, cerebellum) in HV; and mixed (lobar and deep regions) when an individual has coexisting CAA and HV. However, there is no definitive evidence supporting a high diagnostic value of these MB patterns for CAA/HV. First, the aforementioned histopathological studies consisted of small series providing very limited observations, especially regarding lobar MBs and CAA. Second, direct extrapolations from the Boston Criteria for the diagnosis of CAA-related hemorrhage [22] (Table 1) seem inadequate, as they have been validated only in subjects with lobar $\mathrm{ICH}$. At present, it is indirect evidence from population-based studies that mostly supports the associations between lobar/deep MBs and CAA/HV. The Rotterdam Scan 
Table 1 Boston Criteria for diagnosis of cerebral amyloid angiopathy-related hemorrhage [22]

\begin{tabular}{|c|c|}
\hline \multirow[t]{4}{*}{ 1. Definite CAA } & Full post-mortem examination demonstrating: \\
\hline & $\begin{array}{l}\text { - Lobar, cortical, or corticosubcortical } \\
\text { hemorrhage }\end{array}$ \\
\hline & - Severe CAA with vasculopathy ${ }^{a}$ \\
\hline & - Absence of other diagnostic lesion \\
\hline \multirow[t]{4}{*}{$\begin{array}{l}\text { 2. Probable CAA with } \\
\text { supporting pathology }\end{array}$} & $\begin{array}{l}\text { Clinical data and pathologic tissue (evacuated } \\
\text { hematoma or cortical biopsy) demonstrating: }\end{array}$ \\
\hline & $\begin{array}{l}\text { - Lobar, cortical, or corticosubcortical } \\
\text { hemorrhage }\end{array}$ \\
\hline & - Some degree of CAA in specimen \\
\hline & - Absence of other diagnostic lesion \\
\hline \multirow[t]{4}{*}{ 3. Probable CAA } & $\begin{array}{l}\text { Clinical data and magnetic resonance } \\
\text { imaging (MRI) or computed tomography (CT) } \\
\text { demonstrating: }\end{array}$ \\
\hline & $\begin{array}{l}\text { - Multiple hemorrhages restricted to lobar, } \\
\text { cortical, or corticosubcortical regions } \\
\text { (cerebellar hemorrhage allowed) }\end{array}$ \\
\hline & - Age $>55$ years \\
\hline & - Absence of other cause of hemorrhage ${ }^{b}$ \\
\hline \multirow[t]{4}{*}{ 4. Possible CAA } & Clinical data and MRI or CT demonstrating: \\
\hline & $\begin{array}{l}\text { - Single lobar, cortical, or corticosubcortical } \\
\text { hemorrhage }\end{array}$ \\
\hline & - Age $>55$ years \\
\hline & - Absence of other cause of hemorrhage ${ }^{b}$ \\
\hline
\end{tabular}

Criteria were established by the Boston Cerebral Amyloid Angiopathy Group: Steven M Greenberg, Daniel S Kanter, Carlos S Kase and Michael S Pessin. ${ }^{\mathrm{a}} \mathrm{As}$

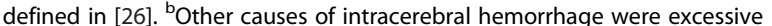
warfarin (international normalized ratio (INR).3.0); antecedent head trauma or ischemic stroke; central nervous system tumor, vascular malformation, or vasculitis; and blood dyscrasia or coagulopathy. (INR.3.0 or other non-specific laboratory abnormalities are permitted for diagnosis of possible cerebral amyloid angiopathy).

Study [16] reported that healthy older individuals with strictly lobar MBs have an exceedingly high frequency of the apolipoprotein E- $\varepsilon 4$ (APOE- $\varepsilon 4$ ) allele (compared with patients with MBs not strictly confined to lobar regions), which is in agreement with increased APOE- $\varepsilon 4$ frequencies seen in patients with 'probable CAA'. In contrast, strictly deep MBs were associated with vascular risk factors, lacunar infarcts, and $\mathrm{WMH}$, but not with the APOE- 84 allele. Associations of mixed MBs resembled the profile of strictly deep MBs. In a subsequent study based on the same population, lobar MBs were seen to occur significantly more often in the temporal lobe [23], one of the regions severely affected by CAA. There still exists another line of investigation providing support to the link between lobar MB and CAA, and it consists of the study of CAA patients with both MRI and Pittsburgh compound $\mathrm{B}$ (PiB)-positron emission tomography (PET) imaging. With this combined approach, a close spatial relationship between MBs and vascular amyloid load was found in a cross-sectional study [24]. Further supporting this observation, PiB retention was shown to rapidly decrease with increasing distance from the MB site [24]. In a later study on a smaller cohort with longitudinal data, the investigators concluded that high-load amyloid areas are a preferential site for development of incidental lobar hemorrhages [25]. Neuroimaging-pathological correlation studies are needed to confirm these associations.

\section{Clinical implications}

Direct pathological observations have demonstrated the existence of tissue damage surrounding MBs [7,15-17]. On a less direct level, diffusion tensor imaging studies have shown an independent association between the presence of MBs and a higher degree of microstructural injury of the brain $[27,28]$. These phenomena provide a scientific basis to support direct clinical effects of MBs, beyond their associations with particular vasculopathies.

Although the underlying mechanism is still a matter of debate, several clinical reports suggest that MBs might cause acute transient focal neurological episodes (TFNEs) $[29,30]$. Clinically, these episodes may resemble transient ischemic attack (TIA) or seizures, depending on the negative or positive character of the symptoms. Pathogenesis might involve direct damage to cells/tracts, but electrical disturbances associated with the leakage of blood components may have a more significant role. In fact, experimental studies have shown that MBs may transiently affect the function of the nearby cells because of an inhibition of stimulus-evoked calcium responses [31]. Recent studies are pointing more toward superficial cortical siderosis, instead of MBs, as the main CAA feature associated with TFNE. Regardless of the exact type of lesion involved, the investigation for evidence of chronic hemorrhages in TIA seems crucial, as the simple initiation of anti-thrombotic therapy could have undesirable effects in cases with TFNE.

The cautious approach to anti-thrombotic therapy in patients with these symptomatic episodes can be extended to all patients exhibiting MBs. From a pathophysiological standpoint, MBs appear to be the expression of a hemorrhage-prone state of the brain, which might carry a greater risk of $\mathrm{ICH}$. In the literature, the risk/benefit ratio of anti-thrombotic drugs in individuals with MBs is controversial, and no formal contraindications in this respect exist. Still, some data support the presence of MBs as an independent risk factor for warfarin-related $\mathrm{ICH}$ [32]. Even anti-platelet agents, traditionally safer than anti-coagulants, have been associated with an increased risk of ICH, especially in subjects with a high number of MBs [33,34]. Given these observations, it seems reasonable to individualize decisions on antithrombotic therapy in patients with MBs. 
A few longitudinal studies have investigated the progression of MBs over time, revealing that MBs at baseline are a risk factor for the development of new MBs [35-37]. According to a follow-up report from the Rotterdam Scan Study, incident lobar and deep MBs have different risk factors [35], similar to what had been observed with baseline MBs [16]. The importance of cumulative $\mathrm{MB}$ burden is double: first, it may produce further widespread damage over brain structures; and, second, it highlights the progression of the underlying SVD. These two factors may explain the impact of baseline identification of MBs on future neurological events and mortality. In a study of individuals with lobar $\mathrm{ICH}$, a higher number of lobar hemorrhages at baseline (including $\mathrm{MBs}$ ) predicted an increased risk of not only lobar $\mathrm{ICH}$ recurrence but also cognitive decline, functional dependence, or death in those individuals not dependent or demented by the time of admission [38]. Mortality was also strongly predicted by MBs (especially when multiple) in another study following patients in a large memory clinic cohort [39]. When specific causes of death according to $\mathrm{MB}$ distribution were investigated in a population-based cohort of older people at high risk of cardiovascular disease, deep MBs were associated with cardiovascular mortality, whereas lobar MBs were associated with stroke-related mortality [40]. These findings fit well with the notion of lobar and deep MBs associated with $\mathrm{HV}$ and CAA, respectively. Since $\mathrm{HV}$ is secondary to a systemic process (hypertension), high cardiovascular mortality is expected in the context; however, CAA is a primary brain vasculopathy, with no extracerebral manifestations.

Apart from ICH, the other main neurological outcomes that have been associated with MBs are gait disturbances [41,42] and cognitive impairment [43]. Cognitive impairment (and dementia) represents an increasing source of severe long-term disability and will be the focus of the review in the next sections.

\section{Microbleed and cognitive impairment}

One of the initial studies assessing the cognitive impact of MBs compared the performance on multiple cognitive domains between patients with and without MBs from a neurovascular clinic [44]. The two subgroups were matched for age, gender, intelligence quotient, extent of $\mathrm{WMH}$, and type and location of ischemic stroke. Individuals with MBs had a much higher prevalence of executive dysfunction than those without MBs $(60 \%$ versus $30 \%, P=0.03)$. In logistic regression analyses, the presence of MBs was the only independent predictor of executive dysfunction. Interestingly, in individuals with executive dysfunction, MBs were predominantly located in the frontal lobes and basal ganglia, areas classically considered the neuroanatomical substrate for executive function. These results suggested that (a) MBs may actually have a negative effect on cognition, independently of other concurrent vascular lesions, and (b) there seems to be an anatomical correlation between the distribution of MBs and the cognitive domains affected, suggesting a direct damage of MBs over the tissue as the pathogenic mechanism. Later studies have confirmed and expanded these findings, using different study populations with different MB patterns. Seo and colleagues [45] investigated the independent effect of MBs in multiple domains in a cohort of individuals with diagnosed subcortical vascular dementia. MBs were predictive not only of executive dysfunction but also of memory, language, and visuospatial impairment. MBs were distributed mostly in the cortical areas, predominantly in the fronto-temporal lobes, and this might suggest a high prevalence of CAA in this cohort. Again, this predominant MB location matched well with the impaired cognitive areas. In the context of Alzheimer's disease (AD), several studies have also explored the relationship between MBs and cognition. We discuss this complex interplay between lobar $\mathrm{MBs}, \mathrm{AD}$, and CAA in detail below.

Both the Age, Gene/Environment Susceptibility (AGES)-Reykjavik study and the Rotterdam Scan Study have reported on MBs and cognitive performance in their respective population-based cohorts. The AGES study $(n=3,906)[46]$ showed that the presence of $M B$, especially multiple MBs, is associated with worse processing speed and executive function. These results were stronger in subjects with strictly deep MBs. It was also seen that the combination of multiple MBs and retinopathy increased the odds ratio of vascular dementia: 3.10; 95\% confidence interval (CI) 1.11 to 8.62 [46]. Taken together, these data firmly provide support that microvascular damage plays a key role in cognitive impairment in older individuals living in the community. Whereas the AGES study confirmed in communitydwelling individuals the suggested link between deep MBs and subcortical cognitive deficits, the Rotterdam Scan Study emphasized the negative effects of lobar MBs on a wider spectrum of cognitive domains [43]. In this study of 3,979 participants, multiple MBs (at least five) were associated with worse cognitive performances in all domains but memory. However, these associations were more robust in individuals with strictly lobar MBs (all analyses adjusted for age, sex, education, vascular risk factors, other SVD markers, and brain atrophy). Differences in baseline characteristics between these two population-based cohorts may explain why deep or lobar location of MBs appears to be more prominent.

In general, the available literature provides support that MBs are independent contributors to cognitive impairment and that their topographic distribution may have specific associations with certain cognitive 
domains. As stated, direct tissue damage or underlying SVD (or both) may account for these detrimental effects.

\section{Lobar microbleed, cerebral amyloid angiopathy, and Alzheimer's disease}

MBs have extraordinary importance in the context of AD. Apart from offering hints on AD pathophysiology, their presence may modify the course of the disease and even the response to new immunotherapeutic agents.

The frequency of $\mathrm{MBs}$ in subjects with $\mathrm{AD}$ varies significantly across studies (16\% to $32 \%$ ) [15,47-50], with a pooled proportion of $23 \%$ (95\% CI $17 \%$ to $31 \%$ ) [51]. Despite this high variability, $\mathrm{MB}$ overall prevalence is consistently higher in subjects with $\mathrm{AD}$ than in nondemented, older individuals [15,50]. Indeed, a recent study using high-field MRI found an MB prevalence as high as $78 \%$ in patients with early AD [7]. Although deep MBs may be identified in some AD cases, the vast majority of them (92\%) show a lobar predominance. As pointed out in population-based studies, lobar MBs are not associated with classic vascular risk factors and show weak associations with other classic SVD markers. Because CAA is present in up to $90 \%$ of AD cases [52], it may be conceptually feasible to state that lobar MBs are reliable markers of CAA in patients with $\mathrm{AD}$. The 'amyloid cascade' hypothesis [53], in combination with further theories on amyloid clearance through perivascular spaces [54], supports this notion. However, it is important to note that only a small proportion of $\mathrm{AD}$ cases (23\%) actually exhibit lobar MBs [51]. There are several ways to explain this dissociation between the postmortem pathological findings of CAA and MB detection during life. First, lobar MBs may appear only in cases with advanced CAA, and advanced CAA accounts for only around $25 \%$ of individuals with dementia [55]. Also, CAA is often reported in autopsies, which by definition reflect end-stage disease, whereas $\mathrm{MB}$ imaging is performed mostly in earlier stages of the disease. Third, the implementation of more sensitive MRI sequences for MB detection will probably increase the proportion of AD patients with lobar MBs.

Despite this, there is a possibility that $\mathrm{AD}$ patients with lobar MBs represent a subgroup with distinct characteristics. This concept has been studied by comparing the cognitive profile, the rate of cognitive decline over time, and the mortality rates between $\mathrm{MB}$ and non-MB subjects with AD. Two early studies failed to demonstrate any influence of MBs on cognitive performance in AD cohorts $[47,49]$. The main limitation of these studies was the use of the Mini-Mental State Examination (MMSE) as the main cognitive outcome measure. Indeed, global cognitive tests (like MMSE) may not capture impairment in certain domains such as executive function. However, a larger study using specific neuropsychological assessments did not find any relationship between MBs and worse cognitive performance [50]. In this case, low MB counts may have prevented this study from identifying associations. More recently, another study overcame this issue by comparing multiple $\mathrm{MB}$ cases with non-MB cases within an $\mathrm{AD}$ cohort. This study showed that AD subjects with multiple MBs had a more severe cognitive impairment (independently of disease duration) and degree of atrophy and WMH [56]. Two studies investigated the value of MBs in predicting progression from mild cognitive impairment to dementia. One of these studies found that the presence of at least one $\mathrm{MB}$ yielded a more than twofold increase, but not a significant risk of non-AD dementia [57]. In the other study, MBs detected on SWI sequences were found to predict cognitive decline in patients followed up to 5 years [58]. Although data are very limited, it is conceivable that lobar MBs could predict progression to AD-type dementia but that deep MBs could anticipate the future development of vascular dementia. In terms of mortality, a study showed that the presence of MBs at baseline in patients from a memory clinic was associated with an increased risk of death, in a dose-dependent fashion and independently of other SVD markers and vascular comorbidity [39]. A later study on the same cohort reported that MBs were not associated with a faster rate of cognitive decline, suggesting that the increase in mortality may be related to other clinical events, like $\mathrm{ICH}[59]$.

Finally, MBs may have some impact on current immunotherapies for $\mathrm{AD}$. An early trial of active immunization reported some cases of severe meningoencephalitis, which prompted its termination [60]. The pathologic study of one of these cases [61] suggested that an inflammatory reaction had been triggered by the immunization agent and targeted $\beta$-amyloid, both in tissue plaques and vessels [62]. Consequently, the presence of advanced CAA has been established as a potential risk factor for developing undesirable brain inflammation in AD immunotherapy. Since lobar MBs in the context of $\mathrm{AD}$ are interpreted as markers of advanced CAA, lobar MB carriers (especially those with multiple MBs) are currently excluded from immunization trials as a safety measure [63]. Although this seems to be a reasonable approach, the precise correlation between MB burden and CAA presence (and severity) is still unknown.

\section{Conclusions}

MBs are SVD markers that carry diagnostic and prognostic information for individuals in various clinical settings. Although our knowledge on MB pathophysiology and clinical implications has increased substantially in the last decades, important questions remain unanswered. The implementation of more sensitive MRI 
techniques for the detection of MBs, and their systematic assessment along with other imaging markers (including PET-based amyloid imaging [24]) and blood biomarkers, may provide a useful tool in the future to guide therapeutic decisions and better define subjects in a research context.

\section{Abbreviations}

AD: Alzheimer's disease; AGES: Age, Gene/Environment Susceptibility; APOE$\varepsilon 4$ : apolipoprotein E-\&4; CAA: cerebral amyloid angiopathy; Cl: confidence interval; GRE: gradient recalled echo; HV: hypertensive vasculopathy; ICH: intracerebral hemorrhage; MB: microbleed; MMSE: Mini-Mental State Examination; MRI: magnetic resonance imaging; PET: positron emission tomography; PiB: Pittsburgh compound B; SVD: small vessel disease: SWI: susceptibility-weighted imaging; TFNE: transient focal neurological episode; TIA: transient ischemic attack; WMH: white matter hyperintensity.

\section{Competing interests}

SMG is the principal investigator in the following grants related to CAA: title: Amyloid Angiopathy, sponsor: National Institutes of Health-National Institute on Aging (NIH-NIA), sponsor number: 5R01AG026484; title: Early Detection of CAA, sponsor: NIH-NINDS, sponsor number: 5R01NS070834. AV is the principal investigator in the following grants related to CAA: title: Project II, sponsor: NIH-NIA, sponsor number: 5P50AG005134; title: Effect of WMD on Gait and Balance in CAA, sponsor: NIH-NIA, sponsor number: 5K23AG028726. SM-R declares that he has no competing interests.

\section{Published: 11 Jun 2014}

\section{References}

1. Roberts TP, Mikulis D: Neuro MR: principles. J Magn Reson Imaging 2007, 26:823-837.

2. Offenbacher H, Fazekas F, Schmidt R, Koch M, Fazekas G, Kapeller P: MR of cerebral abnormalities concomitant with primary intracerebral hematomas. AJNR Am J Neuroradiol 1996, 17:573-578.

3. Vernooij MW, Ikram MA, Wielopolski PA, Krestin GP, Breteler MM, van der Lugt A: Cerebral microbleeds: accelerated 3D T2*-weighted GRE MR imaging versus conventional 2D T2*-weighted GRE MR imaging for detection. Radiology 2008, 248:272-277.

4. Haacke EM, Xu Y, Cheng YC, Reichenbach JR: Susceptibility weighted imaging (SWI). Magn Reson Med 2004, 52:612-618.

5. Nandigam RN, Viswanathan A, Delgado P, Skehan ME, Smith EE, Rosand J, Greenberg SM, Dickerson BC: MR imaging detection of cerebral microbleeds: effect of susceptibility-weighted imaging, section thickness, and field strength. AJNR Am J Neuroradiol 2009, 30:338-343.

6. Cheng AL, Batool S, McCreary CR, Lauzon ML, Frayne R, Goyal M, Smith EE: Susceptibility-weighted imaging is more reliable than $\mathrm{T} 2^{*}$-weighted gradient-recalled echo MRI for detecting microbleeds. Stroke 2013, 44:2782-2786.

7. Brundel M, Heringa SM, de Bresser J, Koek HL, Zwanenburg JJ, Jaap Kappelle L, Luijten PR, Biessels GJ: High prevalence of cerebral microbleeds at 7Tesla MRI in patients with early Alzheimer's disease. J Alzheimers Dis 2012, 31:259-263.

8. Fazekas F, Kleinert R, Roob G, Kleinert G, Kapeller P, Schmidt R, Hartung HP: Histopathologic analysis of foci of signal loss on gradient-echo $\mathrm{T}^{*}$ weighted MR images in patients with spontaneous intracerebral hemorrhage: evidence of microangiopathy-related microbleeds. AJNR Am J Neuroradiol 1999, 20:637-642.

9. Greenberg SM, Vernooij MW, Cordonnier C, Viswanathan A, Al-Shahi Salman R, Warach S, Launer L, Van Buchem MA, Breteler MM: Cerebral microbleeds: a guide to detection and interpretation. Lancet Neurol 2009, 8:165-174.

10. Greenberg SM, Nandigam RN, Delgado P, Betensky RA, Rosand J, Viswanathan A, Frosch MP, Smith EE: Microbleeds versus macrobleeds: evidence for distinct entities. Stroke 2009, 40:2382-2386.

11. Scharf J, Brauherr E, Forsting M, Sartor K: Significance of haemorrhagic lacunes on MRI in patients with hypertensive cerebrovascular disease and intracerebral haemorrhage. Neuroradiology 1994, 36:504-508.

12. Naka H, Nomura E, Wakabayashi S, Kajikawa H, Kohriyama T, Mimori Y, Nakamura S, Matsumoto M: Frequency of asymptomatic microbleeds on
T2*-weighted MR images of patients with recurrent stroke: association with combination of stroke subtypes and leukoaraiosis. AJNR Am J Neuroradiol 2004, 25:714-719.

13. Lee SH, Bae HJ, Kwon SJ, Kim H, Kim YH, Yoon BW, Roh JK: Cerebral microbleeds are regionally associated with intracerebral hemorrhage. Neurology 2004, 62:72-76.

14. Tsushima Y, Aoki J, Endo K: Brain microhemorrhages detected on T2*weighted gradient-echo MR images. AJNR Am J Neuroradiol 2003, 24:88-96.

15. Cordonnier C, van der Flier WM, Sluimer JD, Leys D, Barkhof F, Scheltens P: Prevalence and severity of microbleeds in a memory clinic setting. Neurology 2006, 66:1356-1360.

16. Vernooij MW, van der Lugt A, Ikram MA, Wielopolski PA, Niessen WJ, Hofman A, Krestin GP, Breteler MM: Prevalence and risk factors of cerebral microbleeds: the Rotterdam Scan Study. Neurology 2008, 70:1208-1214.

17. Koennecke HC: Cerebral microbleeds on MRI: prevalence, associations, and potential clinical implications. Neurology 2006, 66:165-171.

18. Tanaka A, Ueno Y, Nakayama Y, Takano K, Takebayashi S: Small chronic hemorrhages and ischemic lesions in association with spontaneous intracerebral hematomas. Stroke 1999, 30:1637-1642.

19. Tatsumi S, Shinohara M, Yamamoto T: Direct comparison of histology of microbleeds with postmortem MR images: a case report. Cerebrovasc Dis 2008, 26:142-146.

20. Schrag M, McAuley G, Pomakian J, Jiffry A, Tung S, Mueller C, Vinters HV, Haacke EM, Holshouser B, Kido D, Kirsch WM: Correlation of hypointensities in susceptibility-weighted images to tissue histology in dementia patients with cerebral amyloid angiopathy: a postmortem MRI study. Acta Neuropathol 2010, 119:291-302.

21. Kikuta K, Takagi Y, Nozaki K, Okada T, Hashimoto N: Histological analysis of microbleed after surgical resection in a patient with moyamoya disease. Neurol Med Chir 2007, 47:564-567.

22. Knudsen KA, Rosand J, Karluk D, Greenberg SM: Clinical diagnosis of cerebral amyloid angiopathy: validation of the Boston criteria. Neurology 2001, 56:537-539.

23. Mesker DJ, Poels MM, Ikram MA, Vernooij MW, Hofman A, Vrooman HA, van der Lugt A, Breteler MM: Lobar distribution of cerebral microbleeds: the Rotterdam Scan Study. Arch Neurol 2011, 68:656-659.

24. Dierksen GA, Skehan ME, Khan MA, Jeng J, Nandigam RN, Becker JA, Kumar A, Neal KL, Betensky RA, Frosch MP, Rosand J, Johnson KA, Viswanathan A, Salat DH, Greenberg SM: Spatial relation between microbleeds and amyloid deposits in amyloid angiopathy. Ann Neurol 2010, 68:545-548.

25. Gurol ME, Dierksen G, Betensky R, Gidicsin C, Halpin A, Becker A, Carmasin J, Ayres A, Schwab K, Viswanathan A, Salat D, Rosand J, Johnson KA, Greenberg SM: Predicting sites of new hemorrhage with amyloid imaging in cerebral amyloid angiopathy. Neurology 2012, 79:320-326.

26. Von Sattel JP, Myers RH, Hedley-Whyte ET, Ropper AH, Bird ED, Richardson EP Jr: Cerebral amyloid angiopathy without and with cerebral hemorrhages: a comparative histological study. Ann Neurol 1991, 30:637-649.

27. Akoudad S, de Groot M, Koudstaal PJ, van der Lugt A, Niessen WJ, Hofman A, Ikram MA, Vernooij MW: Cerebral microbleeds are related to loss of white matter structural integrity. Neurology 2013, 81:1930-1937.

28. Heringa SM, Reijmer YD, Leemans A, Koek HL, Kappelle LJ, Biessels GJ: Multiple microbleeds are related to cerebral network disruptions in patients with early Alzheimer's disease. J Alzheimers Dis 2014, 38:211-221.

29. Greenberg SM, Vonsattel JP, Stakes JW, Gruber M, Finklestein SP: The clinical spectrum of cerebral amyloid angiopathy: presentations without lobar hemorrhage. Neurology 1993, 43:2073-2079.

30. Roch JA, Nighoghossian N, Hermier M, Cakmak S, Picot M, Honnorat J, Derex L, Trouillas P: Transient neurologic symptoms related to cerebral amyloid angiopathy: usefulness of $T 2^{*}$-weighted imaging. Cerebrovasc Dis 2005, 20:412-414.

31. Cianchetti FA, Kim DH, Dimiduk S, Nishimura N, Schaffer CB: Stimulus-evoked calcium transients in somatosensory cortex are temporarily inhibited by a nearby microhemorrhage. PLoS One 2013, 8:e65663.

32. Lee SH, Ryu WS, Roh JK: Cerebral microbleeds are a risk factor for warfarin-related intracerebral hemorrhage. Neurology 2009, 72:171-176.

33. Soo YO, Yang SR, Lam WW, Wong A, Fan YH, Leung HH, Chan AY, Leung C, Leung TW, Wong LK: Risk vs benefit of anti-thrombotic therapy in ischaemic stroke patients with cerebral microbleeds. J Neurol 2008, 255:1679-1686.

34. Biffi A, Halpin A, Towfighi A, Gilson A, Busl K, Rost N, Smith EE, Greenberg MS, Rosand J, Viswanathan A: Aspirin and recurrent intracerebral hemorrhage in cerebral amyloid angiopathy. Neurology 2010, 75:693-698. 
35. Poels MM, Ikram MA, van der Lugt A, Hofman A, Krestin GP, Breteler MM, Vernooij MW: Incidence of cerebral microbleeds in the general population: the Rotterdam Scan Study. Stroke 2011, 42:656-661.

36. Gregoire SM, Brown MM, Kallis C, Jager HR, Yousry TA, Werring DJ: MR detection of new microbleeds in patients with ischemic stroke: five-year cohort follow-up study. Stroke 2010, 41:184-186.

37. Goos JD, Henneman WJ, Sluimer JD, Vrenken H, Sluimer IC, Barkhof F, Blankenstein MA, Scheltens PH, van der Flier WM: Incidence of cerebral microbleeds: a longitudinal study in a memory clinic population. Neurology 2010, 74:1954-1960.

38. Greenberg SM, Eng JA, Ning M, Smith EE, Rosand J: Hemorrhage burden predicts recurrent intracerebral hemorrhage after lobar hemorrhage. Stroke 2004, 35:1415-1420.

39. Henneman WJ, Sluimer JD, Cordonnier C, Baak MM, Scheltens P, Barkhof F, van der Flier WM: MRI biomarkers of vascular damage and atrophy predicting mortality in a memory clinic population. Stroke 2009, 40:492-498.

40. Altmann-Schneider I, Trompet S, de Craen AJ, van Es AC, Jukema JW, Stott DJ, Sattar N, Westendorp RG, van Buchem MA, van der Grond J: Cerebral microbleeds are predictive of mortality in the elderly. Stroke 2011, 42:638-644.

41. de Laat KF, van den Berg HA, van Norden AG, Gons RA, Olde Rikkert MG, de Leeuw FE: Microbleeds are independently related to gait disturbances in elderly individuals with cerebral small vessel disease. Stroke 2011, 42:494-497.

42. Choi P, Ren M, Phan TG, Callisaya M, Ly JV, Beare R, Chong W, Srikanth V: Silent infarcts and cerebral microbleeds modify the associations of white matter lesions with gait and postural stability: population-based study. Stroke 2012, 43:1505-1510.

43. Poels MM, Ikram MA, van der Lugt A, Hofman A, Niessen WJ, Krestin GP, Breteler MM, Vernooij MW: Cerebral microbleeds are associated with worse cognitive function: the Rotterdam Scan Study. Neurology 2012, 78:326-333

44. Werring DJ, Frazer DW, Coward L, Losseff NA, Watt H, Cipolotti L, Brown MM, Jager HR: Cognitive dysfunction in patients with cerebral microbleeds on T2*-weighted gradient-echo MRI. Brain 2004, 127:2265-2275.

45. Seo SW, Hwa Lee B, Kim EJ, Chin J, Sun Cho Y, Yoon U, Na DL: Clinical significance of microbleeds in subcortical vascular dementia. Stroke 2007, 38:1949-1951.

46. Qiu C, Cotch MF, Sigurdsson S, Jonsson PV, Jonsdottir MK, Sveinbjinsdottir S, Eiriksdottir G, Klein R, Harris TB, van Buchem MA, Gudnason V, Launer LJ: Cerebral microbleeds, retinopathy, and dementia: the AGES-Reykjavik Study. Neurology 2010, 75:2221-2228.

47. Nakata Y, Shiga K, Yoshikawa K, Mizuno T, Mori S, Yamada K, Nakajima K: Subclinical brain hemorrhages in Alzheimer's disease: evaluation by magnetic resonance T2*-weighted images. Ann N Y Acad Sci 2002, 977:169-172.

48. Hanyu H, Tanaka Y, Shimizu S, Takasaki M, Abe K: Cerebral microbleeds in Alzheimer's disease. J Neurol 2003, 250:1496-1497.

49. Nakata-Kudo Y, Mizuno T, Yamada K, Shiga K, Yoshikawa K, Mori S, Nishimura T, Nakajima K, Nakagawa M: Microbleeds in Alzheimer disease are more related to cerebral amyloid angiopathy than cerebrovascular disease. Dement Geriatr Cogn Disord 2006, 22:8-14

50. Pettersen JA, Sathiyamoorthy G, Gao FQ, Szilagyi G, Nadkarni NK, St GeorgeHyslop P, Rogaeva E, Black SE: Microbleed topography, leukoaraiosis, and cognition in probable Alzheimer disease from the Sunnybrook dementia study. Arch Neurol 2008, 65:790-795.

51. Cordonnier C, van der Flier WM: Brain microbleeds and Alzheimer's disease: innocent observation or key player? Brain 2011, 134:335-344.

52. Attems J: Sporadic cerebral amyloid angiopathy: pathology, clinical implications, and possible pathomechanisms. Acta Neuropathol 2005, 110:345-359.

53. Hardy J, Selkoe DJ: The amyloid hypothesis of Alzheimer's disease: progress and problems on the road to therapeutics. Science 2002, 297:353-356.

54. Roher AE, Kuo YM, Esh C, Knebel C, Weiss N, Kalback W, Luehrs DC, Childress JL, Beach TG, Weller RO, Kokjohn TA: Cortical and leptomeningeal cerebrovascular amyloid and white matter pathology in Alzheimer's disease. Mol Med 2003, 9:112-122.

55. Arvanitakis Z, Leurgans SE, Wang Z, Wilson RS, Bennett DA, Schneider JA: Cerebral amyloid angiopathy pathology and cognitive domains in older persons. Ann Neurol 2011, 69:320-327.
56. Goos JD, Kester MI, Barkhof F, Klein M, Blankenstein MA, Scheltens P, van der Flier WM: Patients with Alzheimer disease with multiple microbleeds: relation with cerebrospinal fluid biomarkers and cognition. Stroke 2009, 40:3455-3460

57. Staekenborg SS, Koedam EL, Henneman WJ, Stokman P, Barkhof F, Scheltens $P$, van der Flier WM: Progression of mild cognitive impairment to dementia: contribution of cerebrovascular disease compared with medial temporal lobe atrophy. Stroke 2009, 40:1269-1274.

58. Kirsch W, McAuley G, Holshouser B, Petersen F, Ayaz M, Vinters HV, Dickson C, Haacke EM, Britt W 3rd, Larseng J, Kim I, Mueller C, Schrag M, Kido D: Serial susceptibility weighted MRI measures brain iron and microbleeds in dementia. J Alzheimers Dis 2009, 17:599-609.

59. van der Vlies AE, Goos JD, Barkhof F, Scheltens P, van der Flier WM: Microbleeds do not affect rate of cognitive decline in Alzheimer disease. Neurology 2012, 79:763-769.

60. Bayer AJ, Bullock R, Jones RW, Wilkinson D, Paterson KR, Jenkins L, Millais SB, Donoghue S: Evaluation of the safety and immunogenicity of synthetic Abeta42 (AN1792) in patients with AD. Neurology 2005, 64:94-101.

61. Nicoll JA, Wilkinson D, Holmes C, Steart P, Markham H, Weller RO: Neuropathology of human Alzheimer disease after immunization with amyloid-beta peptide: a case report. Nat Med 2003, 9:448-452.

62. Greenberg SM, Bacskai BJ, Hyman BT: Alzheimer disease's double-edged vaccine. Nat Med 2003, 9:389-390.

63. Werring DJ, Sperling R: Inflammatory cerebral amyloid angiopathyand amyloid-modifying therapies: variations on the same ARIA? Ann Neurol 2013, 73:439-441.

\subsection{6/alzrt263}

Cite this article as: Martinez-Ramirez et al:: Cerebral microbleeds: overview and implications in cognitive impairment. Alzheimer's Research \& Therapy $2014,6: 33$ 